BMJ Open

Diabetes

Research

\& Care

\title{
Relationship between baseline physical activity assessed by pedometer count and new-onset diabetes in the NAVIGATOR trial
}

\author{
William E Kraus, ${ }^{1}$ Thomas Yates, ${ }^{2}$ Jaakko Tuomilehto, ${ }^{3,4}$ Jie-Lena Sun, ${ }^{1}$ \\ Laine Thomas, ${ }^{1}$ John J V McMurray, ${ }^{5}$ M Angelyn Bethel, ${ }^{6}$ Rury R Holman ${ }^{6}$
}

To cite: Kraus WE, Yates T, Tuomilehto J, et al. Relationship between baseline physical activity assessed by pedometer count and new-onset diabetes in the NAVIGATOR trial. BMJ Open Diab Res Care 2018;6:e000523. doi:10.1136/ bmjdrc-2018-000523

Received 3 February 2018 Revised 25 May 2018 Accepted 27 June 2018

Check for updates

(c) Author(s) (or their employer(s)) 2018. Re-use permitted under CC BY-NC. No commercial re-use. See rights and permissions. Published by BMJ.

${ }^{1}$ Duke Clinical Research Institute, Duke University School of Medicine, Durham, North Carolina, USA

${ }^{2}$ Diabetes Research Centre, NIHR Leicester Biomedical Research Centre, University of Leicester, Leicester, UK ${ }^{3}$ Professor of Vascular Prevention, Danube-University Krems, Krems an der Donau, Austria

${ }^{4}$ Professor Emeritus, University of Helsinki, Helsinki, Finland ${ }^{5}$ British Heart Foundation Glasgow Cardiovascular Research Centre, University of Glasgow, Glasgow, Scotland ${ }^{6}$ Diabetes Trials Unit, University of Oxford, Oxford, UK

Correspondence to Dr William E Kraus; william.kraus@duke.edu

\section{ABSTRACT}

Objective Physical activity is related to clinical outcomes, even after adjusting for body mass, but is rarely assessed in randomized clinical trials.

Research design and methods We conducted an observational analysis of data from the Nateglinide and Valsartan in Impaired Glucose Tolerance Outcomes Research trial, in which a total of 9306 people from 40 countries with impaired glucose tolerance and either cardiovascular disease or cardiovascular risk factors were randomized to receive nateglinide or placebo, in a 2-by-2 factorial design with valsartan or placebo. All were asked to also participate in a detailed lifestyle modification programme and followed-up for a median of 6.4 years with progression to diabetes as a co-primary end point. Seven-day ambulatory activity was assessed at baseline using research-grade pedometers. We assessed whether the baseline amount of physical activity was related to subsequent development of diabetes in individuals with impaired glucose tolerance.

Results Pedometer data were obtained on 7118 participants and $35.0 \%$ developed diabetes. In an unadjusted analysis each 2000-step increment in the average number of daily steps, up to 10000 , was associated with a $5.5 \%$ lower risk of progression to diabetes (HR $0.95,95 \% \mathrm{Cl} 0.92$ to 0.97 ), with $>6 \%$ relative risk reduction after adjustment.

Conclusions Physical activity should be measured objectively in pharmacologic trials as it is a significant but underappreciated contributor to diabetes outcomes. It should be a regular part of clinical practice as well.

Physical activity is related to a plethora of clinical outcomes, including all-cause mortality, cardiovascular disease (CVD), stroke, and diabetes mellitus. These relationships remain even after adjusting for body mass. ${ }^{12}$ Physical activity is an essential component of a number of lifestyle intervention studies for $\mathrm{CVD}^{3-6}$ and diabetes, ${ }^{7-10}$ but the effects of physical activity alone have rarely been studied prospectively in a clinical trial in subjects at high risk of diabetes or CVD, one exception being the LOOK AHEAD study of

\section{Significance of this study}

What is already known about this subject?

- Regular physical activity prevents development of diabetes mellitus.

What are the new findings?

- Physical activity-measured using a simple pedometer-is an effective measure for objectively measuring physical activity in lifestyle studies and clinical practice.

- There is a highly, clinically significant dose-response relationship of pedometer steps with development of diabetes in a prediabetic population.

How might these results change the focus of research or clinical practice?

$>$ Practitioners caring for those with prediabetes should ask patients to track physical activity with pedometer steps.

- To prevent the development of diabetes, at-risk patients should obtain up 10000 steps per day.

patients with diabetes. ${ }^{11}$ As intensive lifestyle intervention studies are expensive, burdensome, and unlikely to be replicated it may be worthwhile to study relationships of physical activity in long-term clinical outcome trials of individuals with a high burden of risk where secondary observational analyses of these relationships may be more tenable. We have used data from the Nateglinide and Valsartan in Impaired Glucose Tolerance Outcomes Research (NAVIGATOR) Study ${ }^{12}$ for this purpose.

Physical activity was measured objectively using pedometers at baseline in all participants. Data for the association between physical activity and the incidence of CVD have been published previously. ${ }^{13}$ Here we use the baseline pedometer data to address the hypothesis that objectively measured baseline physical activity, irrespective of study 
arm assignment, would be related to the development of diabetes.

\section{RESEARCH DESIGN AND METHODS}

\section{NAVIGATOR and study participants}

NAVIGATOR (ClinicalTrials.gov: NCT00097786) was a double-blind, randomized, placebo-controlled clinical trial with a 2-by-2 factorial design. It evaluated whether valsartan or nateglinide, in addition to lifestyle modification, could reduce the risk of diabetes and cardiovascular events in people with impaired glucose tolerance who either had CVD or risk factors for CVD. ${ }^{1415}$ Details of the trial, including the protocol, results, and design, have been published. ${ }^{121415}$ A total of 9306 participants from 40 countries participated in the trial for a median of 5.0 years for the diabetes outcome.

\section{Lifestyle modification intervention and identification of incident diabetes}

All participants participated in the lifestyle program designed to achieve and maintain a $5 \%$ weight loss; reduce dietary saturated and total fats; and increase physical activity to $150 \mathrm{~min} /$ week. Study staff provided information at each visit in the first year consisting of written materials and videos with reinforcement via telephone contacts. The co-primary outcome of incident diabetes was defined as the development of a fasting plasma glucose $\geq 7.0 \mathrm{mmol} / \mathrm{L}$ and/or 2-hour glucose (measured 2 hours after oral glucose load) $\geq 200 \mathrm{mg} / \mathrm{dL}(\geq 11.1$ $\mathrm{mmol} / \mathrm{L})$, confirmed on oral glucose tolerance test performed within 12 weeks. Diagnoses of diabetes made outside of the study were adjudicated by an independent committee blinded to treatment allocation.

\section{Physical activity measures}

Habitual ambulatory activity was assessed objectively using research-grade pedometers (Accusplit AE120, San Jose, California, USA) in all NAVIGATOR Study centers. The pedometers measured purposeful steps taken through a horizontal, spring-suspended lever arm moving vertically with each step, activating an electric circuit, and registering a step. Two weeks after the initial baseline, clinical measurements were taken, participants were fitted with a pedometer and instructed to wear it during waking hours for seven consecutive days. Participants were given a log book and instructed to write down their daily step counts at the end of each day and then return the log book to the study team.

\section{Statistical analysis}

Continuous variables are reported as medians (25th, 75th percentiles); categorical variables are reported by proportions. Patient characteristics were compared using the Pearson's $\chi^{2}$ test or Fisher's exact test for categorical variables and with the Kruskal-Wallis test for continuous variables. Unadjusted and adjusted Cox proportional hazards regression models were used to assess the associations of physical activity (pedometer steps) with the clinical outcomes. Covariate adjustment was implemented in three stages. First, we report an unadjusted model. Second, we adjusted for age, sex, and region, avoiding other patient characteristics that might be on the causal pathway between exercise and outcome. Third, a fully adjusted model added all variables significantly contributing to the prediction of diabetes in a baseline model in the original study. ${ }^{16}$ These factors or variables are listed in the footnotes of the respective tables.

Using a backward selection technique, the adjustment model was a priori selected as only those factors which at baseline were associated with the incidence of type 2 diabetes in this study.

We tested the proportional hazards assumption and linearity assumption for pedometer steps. As the linearity assumption was not satisfied we tested two spline pieces in our models. Since the second piece was distant from being significant, the pedometer data were truncated at 10000 steps per day. In order to preserve important information on non-missing covariates and improve our multivariable models, pedometer data for the $23 \%$ of missing baseline data were handled by multiple imputation. The final models used five imputed data sets, and the results were combined using valid statistical methods that account for imputation variation. In order to investigate whether imputation affected the strength of results, the analysis was repeated for the subset of 7118 participants with complete data. For all outcomes, two parallel analyses were performed: (1) All patients with pedometer measurements $(n=7118)$. (2) Five imputed data sets. The point estimates of the HRs were very similar for these analyses. Since the results from the complete case and imputed $(\mathrm{n}=9308)$ data sets were similar, we report here only the results from the imputed data. Note, the linearity assumption was not satisfied for pedometer steps; two spline pieces were tested in the model and the final model only included the first piece, which is equivalent to truncating the pedometer steps at 10000 steps per day.

A two-sided $\mathrm{P}$ value $<0.05$ was considered statistically significant for main effects. A $\mathrm{P}$ value $<0.1$ was considered statistically significant for interactions. Statistical analyses were done using SAS V.9.2 (SAS Institute, Cary, North Carolina, USA).

\section{RESULTS}

Baseline pedometer data were obtained on 7118 of the 9306 NAVIGATOR participants. Mean (SD) daily steps by quarters at baseline were 1831 (1151), 4652 (659), 7096 (800), and 11240 (2344) steps per day. table 1 reports biochemical, anthropometric, and behavioral variables of study participants by quartile of baseline pedometer steps, particularly those included in the adjustment models as indicated by notations and in the footnotes.

Table 2 reports the HRs, CIs, and P values for the development of diabetes according to the three models, with figure 1 showing the unadjusted Kaplan-Meier plot. 
Table 1 Baseline characteristics by quartiles of pedometer steps

\begin{tabular}{|c|c|c|c|c|c|}
\hline Characteristic & $\begin{array}{l}\text { Quarter } 1 \\
\text { (N=2326) }\end{array}$ & $\begin{array}{l}\text { Quarter } 2 \\
(\mathrm{~N}=2327)\end{array}$ & $\begin{array}{l}\text { Quarter } 3 \\
\text { (N=2327) }\end{array}$ & $\begin{array}{l}\text { Quarter } 4 \\
(\mathrm{~N}=2326)\end{array}$ & $P$ values \\
\hline $\begin{array}{l}\text { Average daily pedometer steps at month } 0.5 \text {, } \\
\text { median ( } 25 \text { th, } 75 \text { th) }\end{array}$ & $2006(859,2859)$ & $4659(4085,5216)$ & $7093(6382,7754)$ & $105699(9447,12299)$ & $<0.0001$ \\
\hline Age at screening, median (25th, 75 th), years ${ }^{\star}, \dagger$ & $65(59,71)$ & $64(59,69)$ & $63(58,68)$ & $62(57,66)$ & $<0.0001$ \\
\hline Female, no. $(\%)^{*}, \dagger$ & $1259(54.1)$ & $1224(52.6)$ & $1197(51.4)$ & $1031(44.3)$ & $<0.0001$ \\
\hline Pooled race group: original, no. $(\%)^{*}, \dagger$ & & & & & $<0.0001$ \\
\hline White & $1996(85.8)$ & $1985(85.3)$ & $1943(83.5)$ & $1810(77.8)$ & \\
\hline Black & $87(3.7)$ & $58(2.5)$ & $55(2.4)$ & $36(1.5)$ & \\
\hline Asian & $76(3.3)$ & $116(5.0)$ & $145(6.2)$ & $276(11.9)$ & \\
\hline Other & $167(7.2)$ & $168(7.2)$ & $184(7.9)$ & $204(8.8)$ & \\
\hline Current smoker, no. $(\%)^{\star}$ & $319(13.7)$ & $246(10.6)$ & $237(10.2)$ & $223(9.6)$ & $<0.0001$ \\
\hline Region, no. $(\%)^{*}, \dagger$ & & & & & $<0.0001$ \\
\hline Asia & $58(2.5)$ & $96(4.1)$ & $134(5.8)$ & $264(11.3)$ & \\
\hline Europe & $1149(49.4)$ & $1253(53.8)$ & $1279(55.0)$ & $1228(52.8)$ & \\
\hline Latin America & $311(13.4)$ & $332(14.3)$ & $362(15.6)$ & $401(17.2)$ & \\
\hline North America & $716(30.8)$ & $575(24.7)$ & $483(20.8)$ & $372(16.0)$ & \\
\hline Other & $92(4.0)$ & $71(3.1)$ & $69(3.0)$ & $61(2.6)$ & \\
\hline BMI, median (25th, $75 \mathrm{th}), \mathrm{kg} / \mathrm{m}^{2} \dagger$ & $31.2(27.7,35.4)$ & $30.2(27.1,33.9)$ & $29.3(26.7,32.7)$ & $28.4(26.0,31.6)$ & $<0.0001$ \\
\hline Height, median (25th, 75th), cm & $165(158,173)$ & $165(158,172)$ & $165(158,172)$ & $165(159,172)$ & 0.3250 \\
\hline Weight, median (25th, 75th), kg & $85.7(74.3,99.0)$ & $83.0(72.5,94.5)$ & $80.9(71.0,91.3)$ & $79.0(69.1,89.1)$ & $<0.0001$ \\
\hline Waist circumference, median (25th, 75 th), $\mathrm{cm}^{*}$ & $104(96,113)$ & $101(93,110)$ & $99(91,107)$ & $98(89,105)$ & $<0.0001$ \\
\hline Systolic BP, median (25th, 75th), mm Hg† & $140(129,151)$ & $140(129,150)$ & $139(127,150)$ & $139(128,150)$ & 0.0002 \\
\hline Diastolic BP, median (25th, 75th), mm Hg & $82(76,90)$ & $82(76,90)$ & $81(76,90)$ & $82(76,90)$ & 0.5490 \\
\hline Pulse rate, median (25th, 75 th), bpm* & $70.0(64.0,78.0)$ & $70.0(62.0,78.0)$ & $70.0(63.0,76.0)$ & $70.0(62.0,76.0)$ & 0.0142 \\
\hline Family history of diabetes, no. (\%) & $868(37.3)$ & $896(38.5)$ & $882(37.9)$ & $901(38.7)$ & 0.7525 \\
\hline Cardiovascular disease, no. (\%) & $807(34.7)$ & $743(31.9)$ & $706(30.3)$ & $677(29.1)$ & 0.0003 \\
\hline Atrial fibrillation/flutter, no. $(\%)^{*}$ & $112(4.8)$ & $99(4.3)$ & $79(3.4)$ & $66(2.8)$ & 0.0021 \\
\hline Pulmonary embolism/deep vein no. $(\%)^{*}$ & $42(1.8)$ & $34(1.5)$ & $33(1.4)$ & $20(0.9)$ & 0.0499 \\
\hline COPD/emphysema/chronic bronchitis, no. (\%) ${ }^{*}$ & $149(6.4)$ & $118(5.1)$ & $104(4.5)$ & $80(3.4)$ & $<0.0001$ \\
\hline Hypertension, no. (\%) & $1812(77.9)$ & $1827(78.5)$ & $1763(75.8)$ & $1814(78.0)$ & 0.1151 \\
\hline Congestive heart failure, no. $(\%)^{\star}$ & $112(4.8)$ & $80(3.4)$ & $81(3.5)$ & $58(2.5)$ & 0.0003 \\
\hline Left ventricular hypertrophy, no. (\%) & $72(3.1)$ & $62(2.7)$ & $64(2.8)$ & $70(3.0)$ & 0.7886 \\
\hline Cerebrovascular disease no. (\%) & $220(9.5)$ & $186(8.0)$ & $181(7.8)$ & $149(6.4)$ & 0.0019 \\
\hline Coronary heart disease, no. $(\%)^{\star}, \dagger$ & $716(30.8)$ & $669(28.7)$ & $635(27.3)$ & $606(26.1)$ & 0.0026 \\
\hline PAD composite, no. $(\%)^{*}$ & $99(4.3)$ & $90(3.9)$ & $69(3.0)$ & $51(2.2)$ & 0.0003 \\
\hline ECG interpretation, no. (\%) ${ }^{*}$ & & & & & 0.0004 \\
\hline Normal & $1053(45.3)$ & $1095(47.1)$ & $1178(50.6)$ & $1199(51.5)$ & \\
\hline Clinically insignificant abnormality & $884(38.0)$ & $865(37.2)$ & $793(34.1)$ & $784(33.7)$ & \\
\hline Clinically significant abnormality & $389(16.7)$ & $367(15.8)$ & $356(15.3)$ & $343(14.7)$ & \\
\hline Family history of premature CHD, no. (\%) & $386(16.6)$ & $395(17.0)$ & $411(17.7)$ & $352(15.1)$ & 0.1245 \\
\hline Fasting glucose, median (25th, 75 th), $\mathrm{mmol} / \mathrm{L} \dagger$ & $6.1(5.7,6.4)$ & $6.1(5.7,6.4)$ & $6.1(5.7,6.4)$ & $6.1(5.7,6.5)$ & 0.1925 \\
\hline 2-hour glucose, median (25th, 75 th), $\mathrm{mmol} / \mathrm{L} \dagger$ & $9.1(8.4,9.9)$ & $9.1(8.4,9.9)$ & $9.0(8.3,9.9)$ & $9.0(8.3,9.9)$ & 0.0665 \\
\hline HbA1c, median (25th, 75th), \%† & $5.9(5.6,6.2)$ & $5.8(5.6,6.1)$ & $5.8(5.5,6.1)$ & $5.8(5.5,6.0)$ & $<0.0001$ \\
\hline Hemoglobin, median (25th, 75 th), $g / L^{*}, \dagger$ & $146(137,155)$ & $147(138,155)$ & $146(138,155)$ & $148(139,156)$ & 0.0052 \\
\hline LDL cholesterol, median (25th, 75th), mmol// ${ }^{*}, \dagger$ & $3.18(2.53,3.80)$ & $3.21(2.60,3.92)$ & $3.26(2.62,3.95)$ & $3.23(2.63,3.93)$ & 0.0012 \\
\hline HDL cholesterol, median (25th, 75th), mmol/L $†$ & $1.22(1.03,1.46)$ & $1.24(1.04,1.47)$ & $1.24(1.03,1.50)$ & $1.25(1.04,1.48)$ & 0.0227 \\
\hline $\begin{array}{l}\text { Non-HDL cholesterol, median (25th, 75th), } \\
\mathrm{mmol} / \mathrm{L}\end{array}$ & $4.04(3.35,4.75)$ & $4.06(3.41,, 4.86)$ & $4.11(3.46,4.83)$ & $4.04(3.36,4.83)$ & 0.0152 \\
\hline $\begin{array}{l}\text { Non-HDL cholesterol/total cholesterol ratio, } \\
\text { median (25th, 75th) }\end{array}$ & $0.77(0.72,0.81)$ & $0.77(0.72,0.81)$ & $0.77(0.72,0.81)$ & $0.76(0.71,0.81)$ & 0.1095 \\
\hline Total cholesterol, median (25th, $75 \mathrm{th}$ ), $\mathrm{mmol} / \mathrm{L}$ & $5.30(4.62,6.00)$ & $5.39(4.68,6.14)$ & $5.40(4.73,6.16)$ & $5.35(4.66,6.12)$ & 0.0048 \\
\hline
\end{tabular}


Table 1 Continued

\begin{tabular}{|c|c|c|c|c|c|}
\hline Characteristic & $\begin{array}{l}\text { Quarter } 1 \\
(\mathrm{~N}=2326)\end{array}$ & $\begin{array}{l}\text { Quarter } 2 \\
(\mathrm{~N}=2327)\end{array}$ & $\begin{array}{l}\text { Quarter } 3 \\
\text { (N=2327) }\end{array}$ & $\begin{array}{l}\text { Quarter } 4 \\
(\mathrm{~N}=2326)\end{array}$ & $P$ values \\
\hline Triglycerides, median (25th, 75th), mmol/L & $1.8(1.3,2.4)$ & $1.7(1.3,2.4)$ & $1.7(1.2,2.4)$ & $1.6(1.2,2.2)$ & $<0.0001$ \\
\hline eGFR, median (25th, 75 th), $\mathrm{mL} / \mathrm{min} / 1.73 \mathrm{~m}^{2}$ & $77.7(65.4,88.3)$ & $77.8(67.2,89.1)$ & $80.1(69.5,92.0)$ & $82.6(71.3,94.3)$ & $<0.0001$ \\
\hline $\begin{array}{l}\text { Albumin/creatinine ratio, median (25th, } 75 \text { th), } \\
\mathrm{mg} / \mathrm{mmol}\end{array}$ & $0.90(0.55,2.00)$ & $0.84(0.51,1.80)$ & $0.79(0.50,1.56)$ & $0.77(0.50,1.67)$ & 0.0028 \\
\hline $\begin{array}{l}\text { Log of albumin/creatinine ratio, median (25th, } \\
75 \mathrm{th}), \mathrm{mg} / \mathrm{mmol}^{*}\end{array}$ & $-0.11(-0.60,0.69)$ & $-0.17(-0.67,0.59)$ & $-0.24(-0.69,0.44)$ & $-0.26(-0.69,0.51)$ & $<0.0001$ \\
\hline Sodium, median (25th, 75 th), $\mathrm{mmol} / \mathrm{L}^{*}$ & $142(141,144)$ & $142.0(141.0,144.0)$ & $142.0(141.0,144.0)$ & $142.0(141.0,144.0)$ & 0.1052 \\
\hline Potassium, median (25th, 75th), mmol/L & $4.3(4.1,4.6)$ & $4.3(4.1,4.6)$ & $4.3(4.1,4.6)$ & $4.3(4.1,4.6)$ & 0.3125 \\
\hline White blood cell, median (25th, 75 th), $10^{9} / \mathrm{L}$ & $6.9(5.8,8.1)$ & $6.8(5.8,8.0)$ & $6.6(5.7,7.7)$ & $6.5(5.5,7.6)$ & $<0.0001$ \\
\hline Platelet, median (25th, 75th), $10^{9} / \mathrm{L} \dagger$ & $254(215,299)$ & $254(213,297)$ & $252(212,297)$ & $247(207,289)$ & $<0.0001$ \\
\hline Renal dysfunction, no. (\%) & $44(1.9)$ & $20(0.9)$ & $16(0.7)$ & $10(0.4)$ & $<0.0001$ \\
\hline$\alpha$ blocker, no. (\%) & $153(6.6)$ & $153(6.6)$ & $135(5.8)$ & $136(5.8)$ & 0.5188 \\
\hline ACE inhibitor, no. (\%) & $197(8.5)$ & $178(7.6)$ & $157(6.7)$ & $144(6.2)$ & 0.0152 \\
\hline Antihypertensives, no. (\%) & $1778(76.4)$ & $1720(73.9)$ & $1664(71.5)$ & $1654(71.1)$ & $<0.0001$ \\
\hline ARB, no. (\%) & $11(0.5)$ & $10(0.4)$ & $6(0.3)$ & $3(0.1)$ & 0.1396 \\
\hline Aspirin, no. (\%) & $892(38.3)$ & $892(38.3)$ & $833(35.8)$ & $808(34.7)$ & 0.0185 \\
\hline$\beta$ blocker, no. (\%) & 975 (41.9) & $923(39.7)$ & $911(39.1)$ & $857(36.8)$ & 0.0054 \\
\hline Calcium channel blocker, no. (\%) & $784(33.7)$ & 765 (32.9) & $694(29.8)$ & $769(33.1)$ & 0.0226 \\
\hline Diuretic, no. (\%) & $840(36.1)$ & $769(33.0)$ & $714(30.7)$ & $637(27.4)$ & $<0.0001$ \\
\hline Lipid lowering agent, no. (\%) & $907(39.0)$ & $923(39.7)$ & $896(38.5)$ & $851(36.6)$ & 0.1606 \\
\hline
\end{tabular}

*In death, myocardial infarction, or stroke model.

tIn diabetes mellitus baseline model.

ARB, angiotensin receptor blocker; BMI, body mass index; BP, blood pressure; bpm, beats per minute; CHD, coronary heart disease; COPD, chronic obstructive pulmonary disease; eGFR, estimated glomerular filtration rate; HDL, high-density lipoprotein; LDL, low-density lipoprotein; PAD, peripheral arterial disease.

During the study period, $35.0 \%$ (3254 of 9306) of participants developed diabetes. On average, each 2000 greater number of daily steps, up to 10000 , was associated with a $5.5 \%$ lower risk of progression to diabetes (HR 0.95, $95 \%$ CI 0.92 to $0.97 ; \mathrm{P}<0.0001)$ in the unadjusted analysis. The observations remained similar and statistically significant when analyzed adjusting for age, sex, and region of origin (HR $0.95,95 \% \mathrm{CI} 0.92$ to $0.96 ; \mathrm{P}<0.0001$ ), or when analyzed in the fully adjusted model (HR $0.96,95 \%$ CI 0.94 to $0.99 ; \mathrm{P}=0.0042$ ).

To address the potential for effect modification by gender, we tested for an interaction of gender and pedometer steps on outcome for this manuscript and, the $\mathrm{P}$ value was not statistically significant (data not shown).

\section{DISCUSSION}

In this post hoc observational analysis of NAVIGATOR data, a $24 \%$ lower risk of diabetes was seen in those with impaired glucose tolerance and either CVD or cardiovascular risk factors who had a baseline physical activity level of $10000 \mathrm{steps} /$ day compared with 2000 steps/day. In this cohort, change in ambulatory activity is associated with a reduced risk of cardiovascular outcomes. ${ }^{13}$ The findings from this study suggest that a reduced risk of type 2 diabetes may have been one mechanism contributing to this previously observed association.

The data linking regular physical activity with diabetes outcomes derive largely from large population-based

Table 2 Clinical outcomes by every 2000 pedometer steps per day (up to 10 000). Development of diabetes (Using five imputed data sets: $\mathrm{N}=9306$, events=3254; C-index=0.527)

\begin{tabular}{|c|c|c|c|c|c|}
\hline Models & Label & HR & $95 \% \mathrm{Cl}$ & $\chi^{2}$ & $P$ values \\
\hline Unadjusted model & $\begin{array}{l}\text { Average daily pedometer steps per } 2000 \text { greater up to } \\
10000\end{array}$ & 0.95 & 0.92 to 0.97 & 21.74 & $<0.0001$ \\
\hline Adjusted model $1^{\star}$ & $\begin{array}{l}\text { Average daily pedometer steps per } 2000 \text { greater up to } \\
10000\end{array}$ & 0.95 & 0.92 to 0.96 & 24.99 & $<0.0001$ \\
\hline Adjusted model $2 \dagger$ & $\begin{array}{l}\text { Average daily pedometer steps per } 2000 \text { greater up to } \\
10000\end{array}$ & 0.96 & 0.94 to 0.99 & 8.529 & 0.0042 \\
\hline
\end{tabular}

${ }^{*}$ Adjusted for age, sex, and region.

†Adjusted for age; sex; region; race; body mass index; systolic blood pressure; family history of diabetes; composite of history of myocardial infarction (MI), unstable angina, or coronary revascularization; fasting glucose; 2-hour glucose on oral glucose tolerance test; hemoglobin A1C; low-density lipoprotein cholesterol; high-density lipoprotein cholesterol; platelet count; and hemoglobin concentration. 


\section{Kaplan-Meier Curves by 4 groups}

\section{For Outcome:Diabetes}

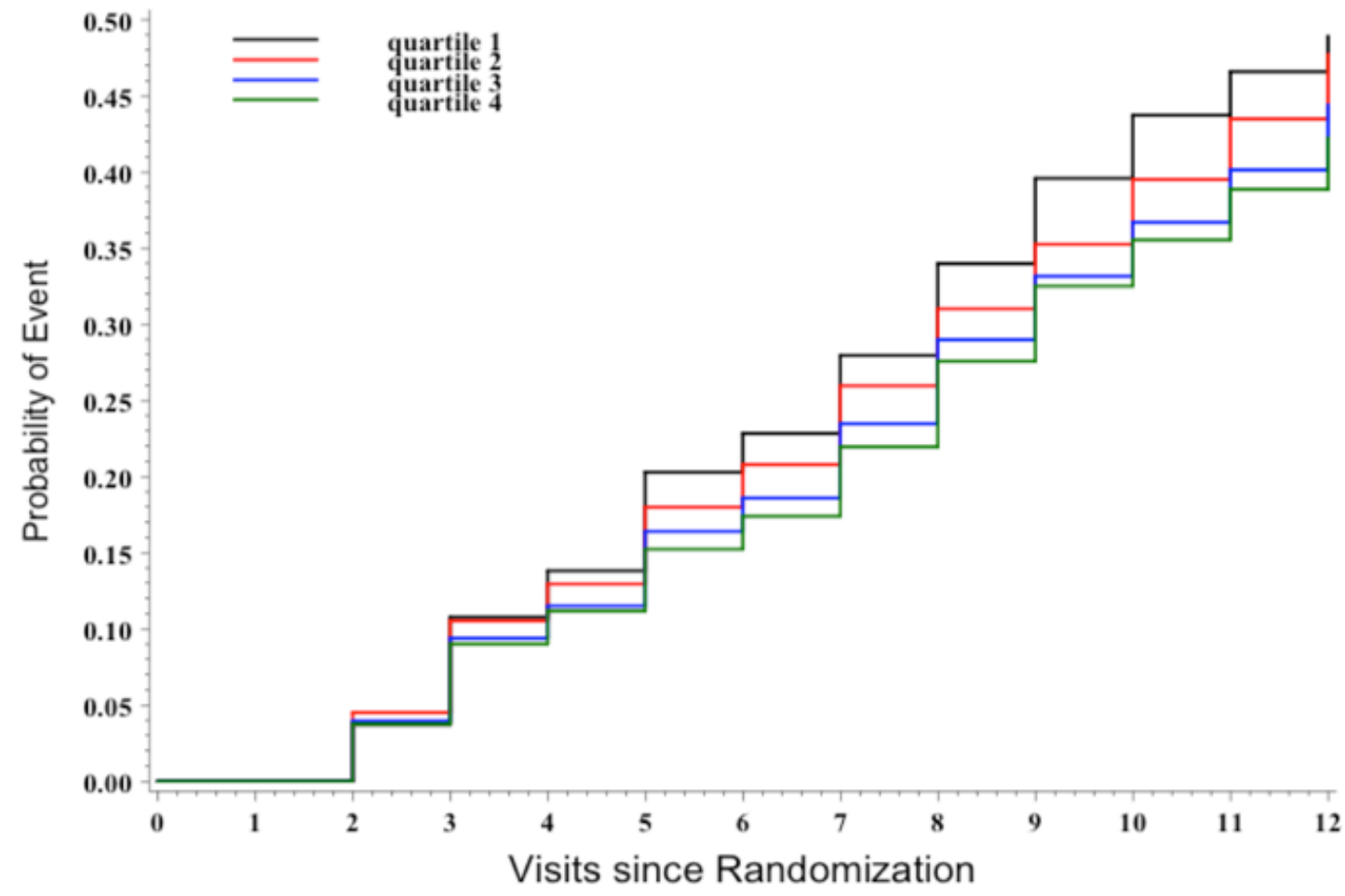

Figure 1 Kaplan-Meier survival curves for the development of diabetes by quartiles of baseline pedometer steps.

Probabilities of diabetes mellitus (DM) curves were compared using log-rank test $(P<0.0001)$. Individuals at risk at each visit of follow-up were: 9306 (V0), 8230 (V1), 7524 (V2), 7178 (V3), 6582 (V4), 6229 (V5), 5572 (V6), 4876 (V7), 4275 (V8), 2931 (V9), and 510 (V10).

cohort studies and were reviewed and summarized in the Surgeon General's Report on Physical Activity and Health $^{1}$ and more recently in the Physical Activity Guidelines Advisory Committee Report ${ }^{2}$ serving as the basis of the 2008 Physical Activity Guidelines for Americans. In the past, most of these data were derived from self-report or survey tools that, while carefully derived and validated, suffered from a number of inherent confounders and limitations associated with such approaches. Recently, the physical activity epidemiology field has begun to rely on objective measures of physical activity, derived from pedometers or accelerometers, to investigate the associations between regular physical activity and cardiometabolic health. ${ }^{17} \mathrm{~A}$ meta-analysis of 17 studies of physical activity in individuals with diabetes shows that each 1 metabolic equivalent hour/day of greater physical activity (roughly equivalent to $20 \mathrm{~min}$ of walking or 2000 steps) incrementally was associated with a $9.5 \%(5.0 \%-$ $13.8 \%) \%)$ and $7.9 \%(4.3 \%-11.4 \%) \%)$ lower risk of all-cause mortality and CVD risk. ${ }^{18}$ The data in this report from the NAVIGATOR Study support and confirm these associations for CVD outcomes in the novel setting of a rigorously conducted and assessed prospective clinical pharmaceutical trial in a large international population broadly representative of those targeted with diabetes and CVD prevention programs in routine clinical care. In the setting of an enriched clinical trial, individuals carry a greater absolute risk for events (in this case diabetes) than would be available in a generalized population-based setting. In addition, the clinical trial setting carries the advantage of regular, close follow-up; standardized collection and adjudication of events; in this case and, most important, repeat and regular follow-up of clinical laboratory testing (eg, oral glucose tolerance testing) to diagnose diabetes mellitus.

The results of the analysis presented here support the independent effects of objectively measured physical activity on metabolic outcomes and the notion that all pharmaceutical studies of incident or established diabetes should consider the independent influence of physical activity levels on the trial outcomes, as is done for other relevant covariates. As physical activity was measured by self-report in the major prevention trials, it has not been possible to use these studies to precisely define the importance of physical activity in the prevention of type 2 diabetes. This study aims to assess the association between physical activity and diabetes progression using an objective measurement tool (a pedometer) with a universally understood metric (steps/day) in the context of an international cohort. 
This study has several strengths. Physical activity was objectively measured using a readily available simple instrument-the pedometer. The collection of a plethora of clinical data on the study subjects, the uniformity of the study population, and the prospective nature of the data collection provide the opportunity to control for a broad range of clinical characteristics strengthening confidence in the strength of the observed associations.

There are several limitations. The study was not designed to test the association between physical activity and diabetes outcomes, opening the possibility for unmeasured confounding. That is, subjects were not randomized on the basis of baseline physical activity; nor were they randomized to changes in physical activity. Further, less active individuals tend to be the least healthy - this is true of any population. We have attempted to account for this by adjustment for a comprehensive list of factors found to be associated with the incidence of type 2 diabetes in the fully adjusted model. However, we acknowledge that confounding by unmeasured confounders-or residual confounding from measured factors-remain possibilities. Still, the dose-response relation between habitual physical activity level and the clinical outcomes provides confidence regarding the fidelity of the observations. Further, since the hypothesis being tested was not a primary study objective, there were missing data on objective measures of physical activity; however, we believe that this limitation was effectively addressed with the imputation and sensitivity analyses. Also, due to the nature of the study tool, we could not address whether intensity of physical activity was related to outcome. That would require accelerometry or another similar tool to address this important question in this setting.

It also is important to make the distinction between physical activity and cardiorespiratory fitness; this study assessed the former, not the latter. There is a strong association between cardiorespiratory fitness and cardiometabolic outcomes as well as all-cause mortality. ${ }^{19-21}$ Further, there is an association between habitual physical activity and cardiorespiratory fitness; however, as genetics play a strong role in the determination of this relation and in cardiorespiratory fitness itself, the relation is far from perfect. The study reported here only applies to the relation of baseline habitual physical activity and incident diabetes mellitus. There was no measure of fitness in this study.

The LOOK AHEAD investigators did not observe a significant effect of a combined lifestyle intervention including physical activity on cardiovascular outcomes in older individuals with type 2 diabetes mellitus. ${ }^{11}$ Several differences in the design of that study and the one reported herein may explain the different observations. Probably the most important difference is in the study populations. LOOK AHEAD studied those with established diabetes, often established for some lengthy period, and NAVIGATOR was designed to study events in those at high risk of developing diabetes, but without frank disease at onset. It may be that the state of the vasculature in those with established disease is not amenable to modification by lifestyle interventions, including physical activity. This distinction would be worth testing in a prospective study. That being said, as they are supported by observations in a recent publication from our group showing that even modest changes in physical activity during the study are reflected in better cardiovascular outcomes, we are confident in the observations reported here. $^{13}$

\section{CONCLUSIONS}

In this secondary analysis of a clinical trial where participants were already at high risk of cardiovascular events and progression to diabetes, each greater 2000-step per day difference in baseline activity (roughly equivalent to 20 min of moderate-paced walking per day) was associated with a $5.5 \%$ lower risk of developing diabetes over the course of the study, even when studied in a fully adjusted model containing other pertinent clinical elements. This observation demonstrates the utility of objective measures of physical activity in clinical trials and suggests that assessments of lifestyle in pharmacologic outcomes trials should be part of regular clinical trials and clinical practice in general.

Contributors WEK wrote the manuscript and researched the data. TY, JT, J-LS, LT, JJVM, MAB, SMH, and RRH reviewed the manuscript critically and contributed to the content. J-LS and LT performed the statistical analysis.

Funding The NAVIGATOR study was supported by Novartis, Inc. TY is supported by the NIHR Diet, Lifestyle and Physical Activity Biomedical Research Unit, Leicester, UK. WEK was supported by NIDDK/NIA grant DK081559 for purposes of this project.

Competing interests TY: Research support from the National Institute for Health Research (NIHR) Leicester Biomedical Research Centre and the NIHR Collaboration for Leadership in Applied Health Research and Care, East Midlands. MAB: Research support from Merck Serono; attended advisory boards with Boehringer Ingelheim, AstraZeneca, and Novo Nordisk. Her department has received research funding from Merck, Amylin, Lilly, and BMS. RRH: Research support from Amylin, Bayer, Merck, and Novartis; attended advisory boards with Amylin, Lilly, Merck, Novartis, and Novo Nordisk; and given lectures supported by Bayer, Lilly, Merck, and Novo Nordisk.

Patient consent Not required.

Ethics approval Duke University.

Provenance and peer review Not commissioned; externally peer reviewed.

Data sharing statement The data contained in this manuscript are held at the Duke Clinical Research Institute.

Open access This is an Open Access article distributed in accordance with the Creative Commons Attribution Non Commercial (CC BY-NC 4.0) license, which permits others to distribute, remix, adapt, build upon this work non-commercially, and license their derivative works on different terms, provided the original work is properly cited and the use is non-commercial. See: http://creativecommons.org/ licenses/by-nc/4.0/

\section{REFERENCES}

1. Surgeon General's report on physical activity and health. From the Centers for Disease Control and Prevention. JAMA 1996;276:522.

2. Physical activity guidelines advisory committee report. Washington DC: US Department of Health and Human Services, 2008.

3. Leon AS, Connett J. Physical activity and 10.5 year mortality in the Multiple Risk Factor Intervention Trial (MRFIT). Int J Epidemiol 1991;20:690-7. 
4. Leon AS, Myers MJ, Connett J. Leisure time physical activity and the 16-year risks of mortality from coronary heart disease and all-causes in the Multiple Risk Factor Intervention Trial (MRFIT). Int J Sports Med 1997;18(Suppl 3):S208-15.

5. The multiple risk factor intervention trial (MRFIT). A national study of primary prevention of coronary heart disease. JAMA 1976;235:825-7.

6. Forum: the multiple risk factor intervention trial (MRFIT). The methods and impact of intervention over four years. Prev Med 1981;10:387-553.

7. Laaksonen DE, Lindström J, Lakka TA, et al. Physical activity in the prevention of type 2 diabetes: the Finnish diabetes prevention study. Diabetes 2005;54:158-65.

8. Tuomilehto J, Lindström J, Eriksson JG, et al. Prevention of type 2 diabetes mellitus by changes in lifestyle among subjects with impaired glucose tolerance. N Engl J Med 2001;344:1343-50.

9. The Diabetes Prevention Program. The diabetes prevention program. Design and methods for a clinical trial in the prevention of type 2 diabetes. Diabetes Care 1999;22:623-34.

10. Li G, Zhang P, Wang J, et al. Cardiovascular mortality, all-cause mortality, and diabetes incidence after lifestyle intervention for people with impaired glucose tolerance in the Da Qing diabetes prevention study: a 23-year follow-up study. Lancet Diabetes Endocrinol 2014;2:474-80.

11. Look AHEAD Research Group, Wing RR, Bolin P, et al. Cardiovascular effects of intensive lifestyle intervention in type 2 diabetes. N Engl J Med 2013;369:145-54.

12. Califf RM, Boolell M, Haffner SM, et al. Prevention of diabetes and cardiovascular disease in patients with impaired glucose tolerance: rationale and design of the Nateglinide And Valsartan in Impaired Glucose Tolerance Outcomes Research (NAVIGATOR) Trial. Am Heart J 2008;156:623-32.
13. Yates T, Haffner SM, Schulte PJ, et al. Association between change in daily ambulatory activity and cardiovascular events in people with impaired glucose tolerance (NAVIGATOR trial): a cohort analysis. Lancet 2014;383:1059-66.

14. NAVIGATOR Study Group, Holman RR, Haffner SM, et al. Effect of nateglinide on the incidence of diabetes and cardiovascular events. N Engl J Med 2010;362:1463-76.

15. NAVIGATOR Study Group, McMurray JJ, Holman RR, et al. Effect of valsartan on the incidence of diabetes and cardiovascular events. $N$ Engl J Med 2010;362:1477-90.

16. Preiss D, Thomas LE, Sun JL, et al. Predictors of cardiovascular events in a contemporary population with impaired glucose tolerance: an observational analysis of the Nateglinide and Valsartan in impaired glucose tolerance outcomes research (NAVIGATOR) trial. BMJ Open 2012;2:e001925.

17. Troiano RP, Berrigan D, Dodd KW, et al. Physical activity in the United States measured by accelerometer. Med Sci Sports Exerc 2008;40:181-8.

18. Kodama S, Tanaka S, Heianza Y, et al. Association between physical activity and risk of all-cause mortality and cardiovascular disease in patients with diabetes: a meta-analysis. Diabetes Care 2013;36:471-9

19. Kodama S, Saito K, Tanaka S, et al. Cardiorespiratory fitness as a quantitative predictor of all-cause mortality and cardiovascular events in healthy men and women: a meta-analysis. JAMA 2009;301:2024-35.

20. Blair SN, Kohl HW, Barlow CE, et al. Changes in physical fitness and all-cause mortality. A prospective study of healthy and unhealthy men. JAMA 1995;273:1093-8.

21. Blair SN, Kohl HW, Paffenbarger RS, et al. Physical fitness and all-cause mortality. A prospective study of healthy men and women. JAMA 1989;262:2395-401. 